\title{
COMPORTAMENTO DE FRENTES DE CONTAMINAÇÃO A PARTIR DE MODELAGEM COM DIFERENTES VALORES DE PARÂMETROS DE SORÇÃO
}

\author{
JANAINA BARRIOS PALMA', LÁZARO VALENTIN ZUQUETTE ${ }^{2} \&$ \\ VAGNER ROBERTO ELIS ${ }^{3}$
}

\begin{abstract}
CONTAMINATION PLUME BEHAVIOR FROM DIFFERENT SORPTION PARAMETERS This paper presents the changes of the contamination plume behaviors for an uncontrolled waste disposal area, in city of Poços de Caldas, State of Minas Gerais, Southeastern of Brazil considering different sorption parameters. Contamination plumes for different times were obtained by numerical simulation using Visual Modflow Software. The results showed that electroresistivity surveys are an adequate tool for acquiring contamination data for calibration of model and monitoring, as well as the importance of the appropriate geological geotechnical studies of the areas, mainly, regarding to geologic material characterization, dispersivity coefficient, hydraulic conductivity, sorption parameters and mineralogy. In reference to sorption, the Langmuir isotherm parameters offered better results than others isotherms.
\end{abstract}

Keywords: Modeling, contamination plume, sorption, solid urban waste, Poços de Caldas, Brazil.

Resumo Neste trabalho são apresentadas as variações no comportamento das frentes de contaminação para a área do lixão da cidade de Poços de Caldas, no Estado de Minas Gerais, quando considerados diferentes valores de sorção. As frentes de contaminação foram obtidas a partir de simulações numéricas. utilizando o programa Visual Modflow. Os resultados demonstram que a eletroresistividade é uma técnica útil para a obtenção de dados de contaminação, usados para calibração de modelos e monitoramento; assim como da importância do adequado conhecimento geológico - geotécnico dos diferentes materiais geológicos, principalmente em termos de coeficientes de dispersividade, condutividade hidráulica, parâmetros de sorção, grau de heterogeneidade e mineralogia. Dentre as isotermas de sorção consideradas nas simulações, a de Langmuir foi a que apresentou melhores resultados dentre as consideradas.

Palavras-chave: Modelagem, plumas de contaminação, resíduos sólidos urbanos, Poços de Caldas, Brasil.

INTRODUÇÃO Líquidos poluídos oriundos dos diferentes tipos de disposição de resíduos e rejeitos migram pelos poros de solos, sedimentos, rochas alteradas e rochas, sujeitos às características hidráulicas e físico-químicas destes. Neste sentido é fundamental conhecer o comportamento da direção e velocidade do fluxo, para prever a extensão e intensidade que os afetam. Dentre os parâmetros considerados nos modelos de transporte, os relacionados a sorção podem afetar profundamente os resultados obtidos, principalmente quando analisados em termos temporais. As características de sorção refletem as relações de adsorção, desorção e precipitação entre os contaminantes das fases líquidas e as características mineralógicas e físico-químicas dos materiais geológicos, e podem variar com o tempo, seja em função de mudanças nas características dos poluentes ou das condições físico-químicas do sistema (material geológico e fase líquida).

O presente trabalho aplica a modelagem numérica na avaliação dos efeitos de diferentes condições de sorção no comportamento do lluxo e do transporte dos poluentes na área do lixão do município de Poços de Caldas, Minas Gerais. A área se enquadra nas usadas para disposição de resíduos urbanos sem estudos geológicos e geotécnicos adequados, e está em atividade deste 1985.

A modelagem matemática de fluxo e de transporte de poluente é ferramenta importante na gestão dos recursos hídricos, e seu uso é relativamente recente e ganhou importância na década de 70 , em função dos avanços computacionais, como no artigo de Dey \& Morison (1979). O Internacional Groundwater Modeling Center of the Holocomb Institute, Universidade de Butter, Indianapolis, Indiana, catalogou mais de 400 modelos de fluxo e transporte de solutos, sendo que, no mínimo, 100 foram considerados eficientes.

Vários trabalhos analisam a validade da modelagem numérica e comparam seus resultados com valores obtidos pela aplicação de modelos analíticos e dados de campo. Olsthoorn (1999) estudou duas áreas com o uso do programa MODFLOW e o modelo analítico MLAEM - Analytic Element Method Mutilayer, e conclui que a escolha do modelo é função do objetivo do trabalho e características do local.

Neste trabalho utilizou-se o modelo USGS Modular 3D Finite Difference Groundwater Flow Model, ou MODFLOW (McDonald \& Harbaugh 1988) e o Modular 3D Finite Difference Mass Transport Model, ou MT3D (Zheng 1992). As principais vantagens destes programas são a rapidez e facilidade para simular diferentes cenários após a definição do modelo conceitual, a boa interação com o usuário, a atualização constante do programa, o desenvolvimento de programas compatíveis como o Modpath e o Winpest, a interface gráfica com programas como Visualgroundwater, Groundwater Vistas, a interação com programas gerais como

\footnotetext{
I - Departamento de Geotecnia - Escola de Engenharia de São Carlos. Universidade de São Paulo - Av. Trabalhador São-Carlense, 400. Cep 13560-250. Sào Carlos. SP. Fax: (16) 273-95(29) - Email: janainapalma@hotmail.com

2 - Departamento de Geotecnia - Escola de Engenharia de São Carlos. Universidade de São Paulo - Av. Trabalhador São-Carlense, 400. Cep 13560-250. São Carlos. SP. - Fax: (16) 273-9509 - Email: lazarus1@sc.usp.br

3 - Departamento de Geofísica - Instituto Astronômico e Geofísico. Universidade de São Paulo - Rua do Matão, 1226. São Paulo. SP. - Fax: (11) 38185034 - Email: vagnelis@iag.usp.br
} 
PEST e UCODE, e as ferramentas próprias para calibração como o MODINV e o MODFLOWP (Olsthoorn 1999, Winston 1999).

A maioria dos programas admite apenas tensores de dispersão hidrodinâmico em meio poroso isótropo. O programa Modflow visa uma situação mais próxima da natural, utiliza os valores de dispersão como proposto por Burnett \& Frind (1987), e permite simular com parâmetros de dispersividade transversal, vertical e horizontal (Dxx, Dyy, Dzz, Dxy, Dxz e Dzy). Como não há dados precisos para os materiais geológicos da área, considerou-se valores de dispersividade obtidos por meios empíricos.

A principal limitação do programa Modflow reside em considerar apenas o fluxo em zona saturada e não permitir simular camadas em forma de lente. No caso do lixão de Poços de Caldas a base dos resíduos está em contato direto com a zona saturada, desta forma o programa pode ser utilizado independente desta deficiência, assim como as camadas geológicas, embora com geometria variada, apresentam continuidade horizontal.

Foram realizados trabalhos de campo, sondagens com trados, ensaios geofísicos de eletroresistividade e análises laboratoriais. Os trabalhos de campo e as sondagens visaram caracterizar os materiais inconsolidados e rochosos, e os ensaios de eletroresistividade caracterizar a frente de contaminação e as intensidades.

CARACTERÍSTICAS GERAIS DA ÁREA A cidade de Poços de Caldas localiza-se na porção nordeste do Maciço Alcalino homônimo, com uma população de 122.000 habitantes. A área têm coordenadas de referência $46^{\circ} 34^{\prime} 00^{\prime \prime} \mathrm{W}$ e $21^{\circ} 53^{\prime} 00^{\prime \prime} \mathrm{S}$ e está cerca de $12 \mathrm{Km}$ da área urbana de Poços de Caldas, próxima à rodovia Poços de Caldas - Andradas (Fig. 1), à margem esquerda do Córrego Retiro dos Moinhos, na Bacia do Rio das Antas.

O clima é do tipo Cwb de Köppen, entre o grupo A, dos climas tropicais quentes, e o grupo $\mathrm{C}$ dos mesotérmicos, com inverno seco e verão chuvoso. Segundo a Secretaria de Ciências e Tecnologia do Estado de Minas Gerais os valores anuais médios dos indicadores climáticos são: precipitação de $1.700 \mathrm{~mm}$; temperatura de $18{ }^{\circ} \mathrm{C}$; umidade relativa de $76,5 \%$; evapotranspiração real de $850 \mathrm{~mm}$. A direção preferencial dos ventos é no sentido N-NE.

Substrato Rochoso As rochas da bacia hidrográfica do Córrego Retiro dos Moinhos são nefelina sienitos e fonolitos (Fig 2). Dentre os últimos predominam egerina fonolito, fonolito porfirítico e pseudoleucita fonolito. São afaníticos a faneríticos finos, raramente médios, cinza esverdeado a preto, constituídos por nefelina e, em menor proporção, analcima e sodalita. O piroxênio pode atingir 20\% e o anfibólio é mais raro. Os nefelina sienitos são maciços, leucocráticos, constituídos por nefelina e ortoclásio. Piroxênio, biotita e acessórios atingem até $10 \%$.

Materiais Inconsolidados Quanto á gênese, os materiais inconsolidados foram classificados em quatro tipos (Geological Society 1990): os materiais retrabalhados, reliquiares, residuais e de aterro (Fig. 3).

Os retrabalhados, representados por aluviões e colúvios ocorrem nos talveques dos principais canais de drenagem. Os residuais têm alto grau de heterogeneidade e guardam poucas características da rocha original. Os reliquiares mantêm as características das rochas originais e podem atingir até $10 \mathrm{~m}$ de espessura. A camada de aterro ocorre nas áreas onde foi explorada bauxita até profundidades da ordem de $4 \mathrm{~m}$, e suas cavas foram aterradas com blocos e materiais inconsolidados não aproveitados como minério ou materiais trazidos de outras áreas.
Os ensaios realizados em amostras deformadas retiradas a cada $50 \mathrm{~cm}$ até a profundidade de $11 \mathrm{~m}$ revelaram $\mathrm{pH}$ entre 6 e 8 , capaci-

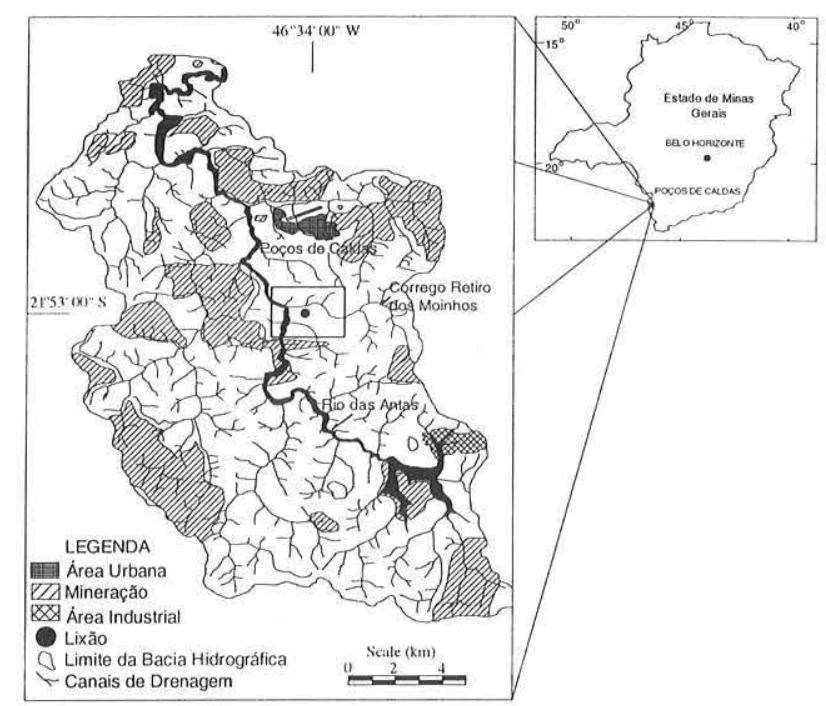

Figura 1-Localização da área em estudo, usos e ocupações da Bacia do Rio das Antas.

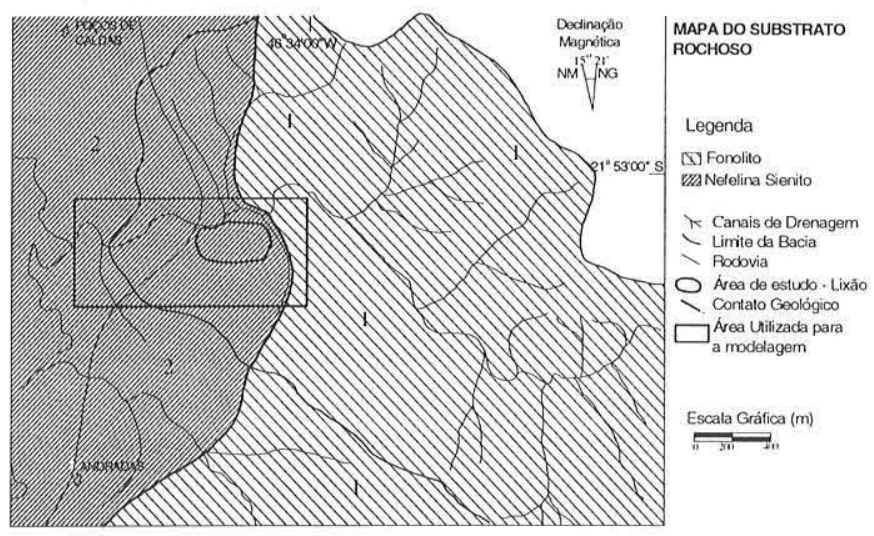

Figura 2 - Mapa do Substrato Rochoso e posição do lixão e da área utilizada para a modelagem.

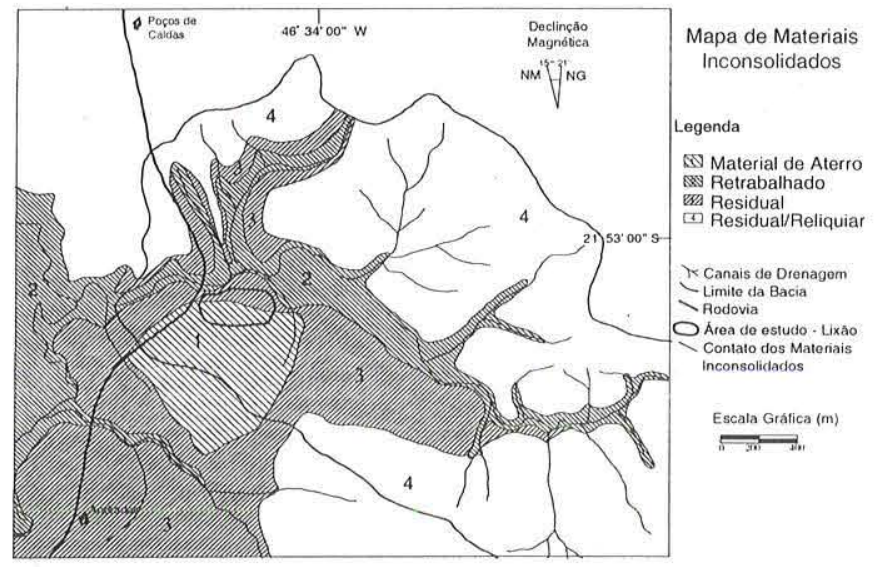

Figura 3 - Mapa de materiais inconsolidados 
dade de troca catiônica inferior a $5 \mathrm{cmol}(+) / \mathrm{Kg}$ de material e superfície específica menor que $50 \mathrm{~m}^{2} / \mathrm{g}$.

Características Hidrogeológicas Sondagens Elétricas Verticais (SEV), caminhamento elétrico dipolo-dipolo e sondagens dipolares, desenvolvidas por Elis (1999) auxiliaram na elaboração do mapa de fluxo subsuperficial e na definição da espessura dos resíduos dispostos e dos materiais inconsolidados.

As SEVs definiram a camada de resíduos, com resistividade entre 5,6 e 11,2 ohm.m, uma camada com resistividade entre 25 e 87 ohm.m interpretada como solo saturado na base do aterro e outra de alta resistividade (> $1450 \mathrm{ohm} . \mathrm{m}$ ) interpretada como saprolito ou sienito alterado. As sondagens dipolares indicaram que a base dos resíduos coincide com a zona saturada. Os ensaios de caminhamento elétrico expressos como mapas de resistividade aparente, mostram a evolução da frente de contaminação entre 2 medidas realizadas com 850 dias de diferença.

A recarga estimada para a área é de $340 \mathrm{~mm} / \mathrm{ano}$ e equivale à $20 \%$ da precipitação total, está condicionada à condutividade hidráulica elevada do material inconsolidado e dos resíduos, à baixa declividade $(<4 \%)$ e às feições superficiais armazenadoras que impedem o escoamento superficial que aumentam o tempo de permanência das águas na superfície e portanto o volume infiltrado.

CARACTERÍSTICAS DOS RESÍDUOS Os resíduos urbanos e hospitalares gerados no município são dispostos neste local desde 1985 e, atualmente, depositadas 60 toneladas/dia de resíduos urbanos residenciais, 5 toneladas/dia decorrentes dos serviços da saúde, e 15 toneladas/dia proveniente das industrias comuns e do comércio. A área ocupa $33.000 \mathrm{~m}^{2} \mathrm{com}$ volume aproximado de $250.000 \mathrm{~m}^{3}$, e espessura média de $7,5 \mathrm{~m}$.

Os resíduos são cobertos por uma camada de poucos centímetros de material argiloso compactado. Contudo, não há nenhum procedimento de controle da poluição das águas e materiais geológicos como uma camada de baixa condutividade hidráulica ou um sistema coletor de lixiviado e gás.

BASES PARA A SIMULAÇÃO Para desenvolver a simulação foi admitida uma área de $1230 \mathrm{~m}$ de comprimento por $540 \mathrm{~m}$ de largura (Fig. 2). Tais dimensões foram estipuladas para avaliar a extensão longitudinal da frente de contaminação e evitar a inclusão de áreas de alta decilvidade no modelo, as quas afetam os resultados, mas sem real importância no fluxo dos poluentes.

Para a discretização espacial das células criou-se uma malha horizontal regular de 82 colunas por 36 linhas, com células de $15 \times 15 \mathrm{~m}$. Para a discretização vertical, o pacote de materiais geológicos foi dividido em 3 camadas (Fig. 4), de acordo com a condutividade hidráulica dos materiais inconsolidados (Tabela 1). O tempo adotado para a discretização temporal foi de 0 até 7300 dias (20 anos), com intervalos de 1825 dias.

Calibração Os valores utilizados na calibração foram obtidos por Elis (1999), e delimitam a frente de contaminação em valores de resistividade elétrica aparente. Para correlacionar estes valores com a concentração de sólidos totais dissolvidos (TDS) utilizouse a equação 1 (Meju (2000):

$$
\text { TDS }=-54.4+7.04 \sigma w(1)
$$

onde $\sigma_{w}$ é a condutividade elétrica da solução aquosa em $\mathrm{mS} / \mathrm{m}$ $\left(\sigma_{W}=1000 /\right.$ Resistividade $)$ e TDS em mg/l. A opção por esta expressão deveu-se à grande quantidade de dados para seu desenvolvimento e considerar valores obtidos também em outros lixões

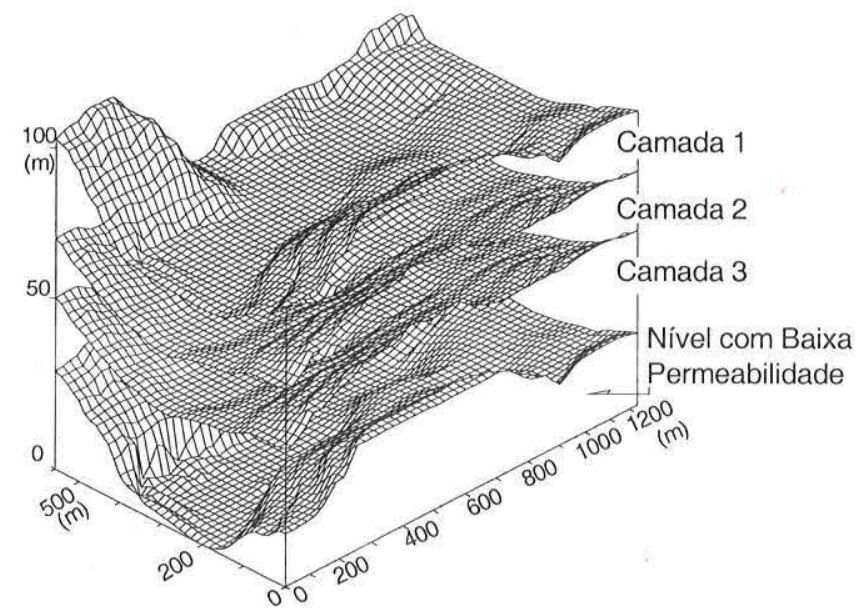

Figura 4-Representação da geometria das camadas do modelo.

Tabela 1 - Camadas adotadas para a modelagem.

\begin{tabular}{ccccc}
\hline Camadas & $\begin{array}{c}\text { Material } \\
\text { Inconsolidado }\end{array}$ & $\begin{array}{c}\text { Condutividade } \\
\text { Hidráulica }\end{array}$ & $\begin{array}{c}\text { Porosidade } \\
\text { total }\end{array}$ & $\begin{array}{c}\text { Porosidade } \\
\text { efetiva }\end{array}$ \\
\hline Camada 1 & Residual & $1,2.10^{-4} \mathrm{a} 1.10^{-3} \mathrm{~m} / \mathrm{s}$ & 0.38 & 0.3 \\
Camada 2 & Reliquiar & $1.10^{-5} \mathrm{~m} / \mathrm{s}$ & 0.36 & 0.25 \\
Camada 3 & Reliquiar & $1.10^{-7} \mathrm{~m} / \mathrm{s}^{*}$ & 0.3 & 0.2 \\
Base & Rocha - Sienito & $5,4.10^{-10} \mathrm{~m} / \mathrm{s}^{*}$ & $0.30^{* *}$ & $0.20^{* *}$ \\
\hline
\end{tabular}

* dados obtidos de Carlstron Filho et al. (1978).

** dados não utilizados na modelagem.

do território brasileiro. As figs. 5a e b apresentam os valores utilizados na calibração, equivalentes aos tempos de 3650 e 4380 dias, respectivamente, e para a profundidade de $10 \mathrm{~m}$.

Além das informações utilizadas para a calibração, outros resultados de geofísica foram úteis para o conhecimento da geometria da pluma e para a escolha da simulação que mais se aproximou da condição natural. Estes resultados não apresentam continuidade temporal, mas delimitam a pluma espacialmente na forma de mapas a diversas profundidades (Figs. 6 e 7).

Considerações Gerais sobre as condições simuladas Os principais mecanismos que afetam o transporte dos solutos são a adveç̧ão, a dispersão hidrodinâmica, a sorção e o decaimento de primeira ordem. Durante a evolução da frente de contaminação a advecção tende a ser a principal responsável pelo movimento do fluxo. A dispersão hidrodinâmica é feita de forma mecânica e por difusão molecular. A dispersão mecânica refere-se ao espalhamento longitudinal e transversal à direção principal de fluxo, com diluição gradual dos poluentes. A difusão molecular é o transporte causado por diferentes gradientes de concentração de espécies químicas do meio.

Sorção - Aspectos básicos Sorção é um termo geral da relação entre fases sólida e líquida (concomitantes), e refere-se à transferência de material do líquido para a interface das fases sólidas. Este termo é utilizado quando é difícil distinguir entre os mecanismos de adsorção (física e química) e precipitação.

Considera-se precipitação quando há transferência de soluto da fase aquosa para a superfície da fase sólida, resultando em uma nova substância, com uma nova fase sólida cristalina. A precipitação ocorre em 2 fases, de nucleação e de crescimento da partícula, 
e pode ocorrer na superfície das partículas ou nos poros interssticiais. $\mathrm{O}$ pH do material geológico e da fase líquida, o Eh, e a concentração dos contaminantes são os principais controladores deste processo.

Quando líquidos poluídos percolam os materiais geológicos, parte dos íons e/ou moléculas podem ser adsorvidos pelas partículas minerais ou materiais orgânicos. Tal processo ocorre até uma condição de equilíbrio de absorção, e poderá modificar-se quando um ou mais dos atributos controladores $(\mathrm{pH}$, pressão e temperatura) forem alterados. A relação entre a concentração adsorvida e a concentração em equilíbrio é denominada de isoterma de adsorção e que comumente é compreende quatro categorias: isotermas S, L, HeC (Fig. 8).

Dentre as 4 categorias, a L e a C são encontradas em materiais geológicos, sendo que a L é conhecida em termos matemáticos como equações de Langmuir ou Freundlich e a C, como linear.

A taxa de adsorção depende da carga eletrostática das partículas dos materiais geológicos, e, em solos de clima tropical, são geralmente variáveis (positiva e negativa) resultantes da assembléia mineralógica e do $\mathrm{pH}$.

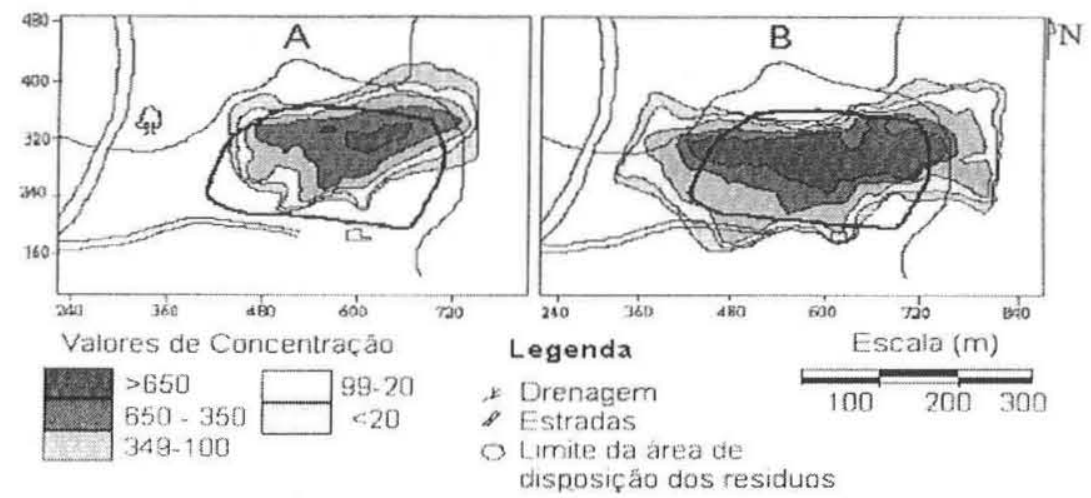

Figura 5 - Delimitação da frente de contaminação a partir de ensaios geofísicos para a profundidade de $10 \mathrm{~m}$. (A) - Tempo de 3650 dias e (B) - tempo de 4380 dias (Elis 1998).

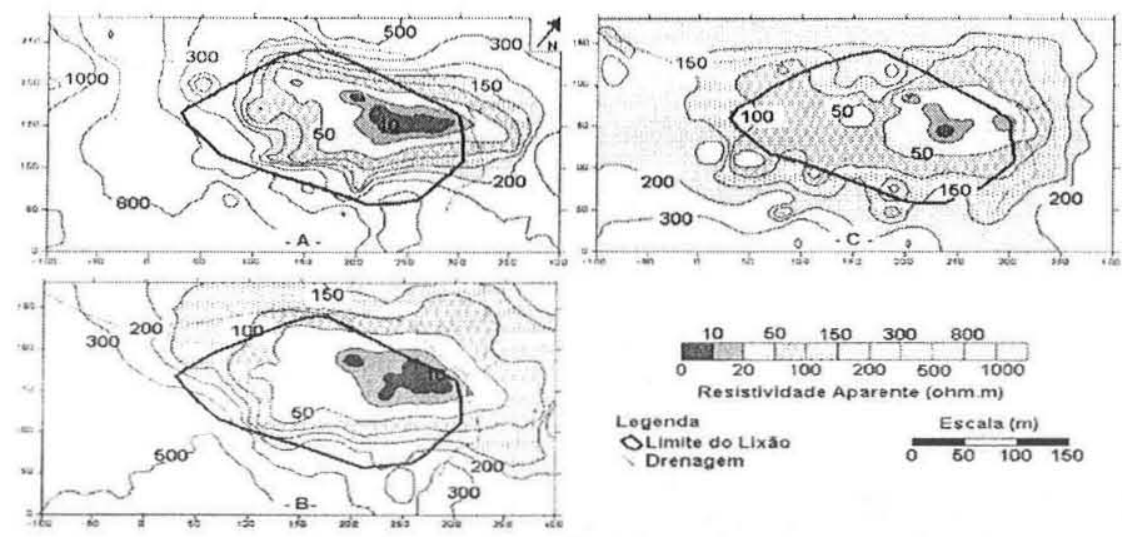

Figura 6 - Delimitação da frente de contaminação a partir de ensaios geofísicos em diversas profundidades (A) $10 \mathrm{~m}$, (B) 20m e (C) $30 \mathrm{~m}$, para o tempo de 4380 dias (Elis 1998).

Ensaio realizado em 23.04.1996 (Equivalente ao Tempo de 4380 dias)

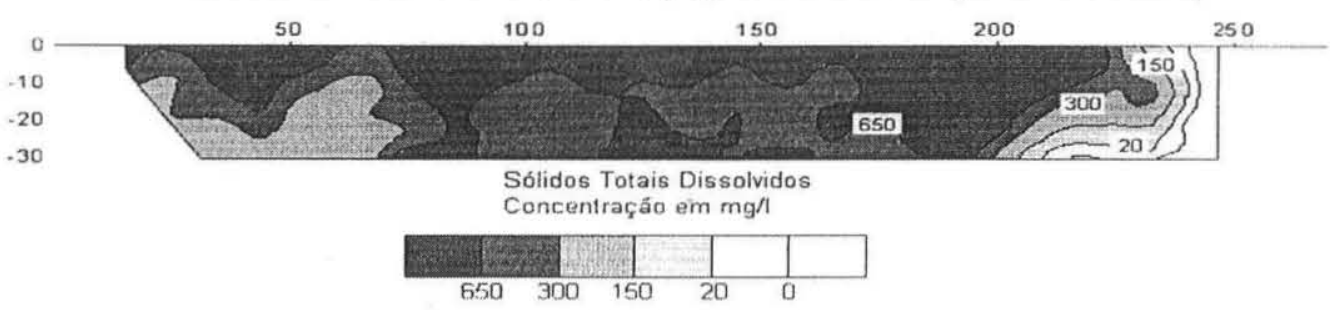

Figura 7 - Delimitação da frente de contaminação a partir de ensaios geofísicos, perfil no sentido leste-oeste (parte tracejada da linha E-W na Figura 9); do domínio do lixão (Elis 1998). 
Para um determinado valor de $\mathrm{pH}$, o balanço das cargas superficiais variáveis pode ser nulo e denominado de $\mathrm{pH}_{\mathrm{o}}$ do componente carga variável (ponto de carga Zero), e ponto de efeito salino zero (PESZ) para cargas variáveis e permanentes. Quando a carga permanente for zero, o $\mathrm{pH}_{\mathrm{o}}$ será igual ao PESZ.

A sorção é normalmente representada por isotermas obtidas em ensaios de laboratório por (1) reação de um material geológico e uma solução aquosa, com composição conhecida, sob uma temperatura e pressão e para um período de tempo (Batch test) ou (2) determinação da composição química do solo e da solução.

Os ensaios devem ser realizados durante intervalos de tempo suficientes para que haja máxima sorção, mas não tão extensos a ponto de ocorrer reações químicas não consideradas na sorção (adsorção e precipitação). Assume-se que ocorre uma condição de equilíbrio entre as fases líquida e sólida, e que a reação de sorção seja rápida o suficiente para ser considerada instantânea quando comparada com a velocidade da água subsuperficial.

Neste trabalho foram testadas várias situações os emcanismos citados de diferentes formas. Este procedimento visou analisar as diferentes possibilidades das condições naturais. As condições de dispersividade e o mecanismo de advecção foram considerados iguais em todas as simulações, sendo o calculo da velocidade feito por interpolação simples por parte proposta por Pollock (1988), que é o processo utilizado como base no Modflow.

Definição dos Cenários Para equacionar os diferentes cenários de simulação e obter as distâncias e intensidades atingidas pela frente de contaminação, considerou-se a área do Lixão constante $\left(33.000 \mathrm{~m}^{2}\right)$ e os seguintes aspectos geológico-geotécnico: distribuição espacial dos materiais geológicos, características físicas e hidráulicas, climáticas (precipitação, evapotranspiração, recarga) e dispersividade dos materiais geológicos (Tabela 2). A dispersividade longitudinal e as razões entre dispersividades transversais e verticais foram obtidas a partir de relações entre as características dos materiais inconsolidados e das extensões da área em função da escala de trabalho.

Os valores das colunas da Tabela 2 representam: 1 - massa específica aparente; 2 - condutividade hidráulica $(\mathrm{m} / \mathrm{s}) ; 3$ - porosidade efetiva; 4 - porosidade total; 5 - capacidade de campo $\left(\mathrm{m}^{3} / \mathrm{m}^{3}\right) ; 6$ armazenabilidade $\left(\mathrm{m}^{3} / \mathrm{m}^{3}\right) ; 7$ - dispersividade longitudinal $(\mathrm{m}) ; 8$ razão entre dispersividade horizontal e longitudinal; 9 - razão entre dispersividade vertical e longitudinal; 10 - coeficiente de difusão molecular $\left(\mathrm{cm}^{2} / \mathrm{s}\right) ; 11$ - coeficiente de sorção - $\mathrm{Kd} \mathrm{-} \mathrm{m}^{3} / \mathrm{Kg}$ (linear); $\alpha-\mathrm{m}^{3} / \mathrm{kg}$; e $\beta-\mathrm{Kg} / \mathrm{Kg}$ (Langmuir) e $\mathrm{N}-\mathrm{m}^{3} / \mathrm{Kg}$; e $\mathrm{K}-\mathrm{Kg} / \mathrm{Kg}$ (Freundlich).

Parâmetros de Sorção Os materiais inconsolidados da área são constituídos por proporções variadas de argila (caulinita), hidróxidos de alumínio (gibsita), matéria orgânica, quartzo, óxidos de ferro (hematita e magnetita) e goetita. Algumas características destes minerais encontram-se nas Tabelas 3, 4 e 5 .

Em solos de clima tropical, as cargas dos minerais predominantes são variáveis. A Tabela 4 lista alguns minerais e as porcentagens de carga negativa permanente e carga variável, proveniente do comportamento anfótero de suas bordas. Contudo, os vários minerais destes solos apresentam diferenças significativas de valores do ponto de carga zero (Tabela 5).

Forbes et al. (1974) verificaram que as diferenças na adsorção seletiva foram induzidas pelas propriedades do solo e dos metais pesados. A Tabela 6 mostra a ordem de seletividade destes metais estabelecida para diferentes constituintes do solo.

Com base nas características dos diferentes materiais geológi$\cos$ (mineralogia, CTC e pH) e considerando os possíveis constituintes inorgânicos nos líquidos oriundos de resíduos urbanos, foram selecionados para análise dos parâmetros de sorção dos íons $\mathrm{K}^{+}$e $\mathrm{Cd}^{++}$, representativos dos dois grupos mais comuns de íns, os alcalinos e os metálicos.

Quanto a isotermas, considerou-se a linear e a de Langmuir, em função das baixas concentrações de poluentes. Neste caso, a Isoterma Linear pode gerar resultados interessantes para análise e

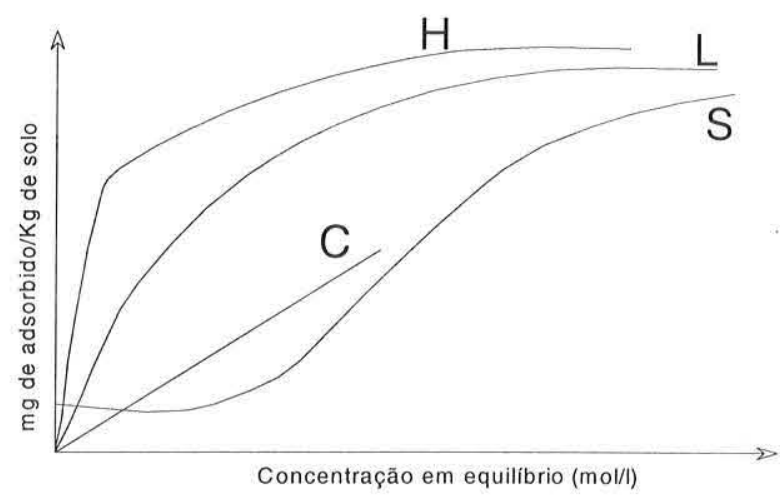

Figura 8-Tipos clássicos de isotermas de adsorção.

Tabela 2 - Parâmetros geotécnicos, hidráulicos, de dispersividade e sorção considerados para os cenários simulados.

\begin{tabular}{|c|c|c|c|c|c|c|c|c|c|c|c|c|c|}
\hline Cenários & Camada & $1^{* * * *}$ & $2^{\text {w水 }}$ & 3 *** & $4^{\text {**** }}$ & $5^{* * *}$ & $6^{* * *}$ & $7^{* * *}$ & $8^{* * *}$ & 9** & $10^{* * *}$ & 11 & *** \\
\hline \multirow{3}{*}{1} & 1 & 1700 & $1,2.10^{-4}$ & 0.3 & 0.38 & 0.19 & 0.0001 & 0.1 & 0.1 & 0.01 & $8,6 \cdot 10^{-6}$ & **** & \\
\hline & 2 & 1700 & $1.10^{-5}$ & 0.25 & 0.36 & 0.19 & 0.0001 & 0.1 & 0.1 & 0.01 & $8,6 \cdot 10^{-6}$ & **** & \\
\hline & 3 & 1700 & $1.10^{-7}$ & 0.2 & 0.3 & 0.19 & 0.0001 & 0.05 & 0.01 & 0.01 & $8,6 \cdot 10^{-6}$ & $* * *$ & \\
\hline \multirow{3}{*}{2} & 1 & 1700 & $1,2.10^{-4}$ & 0.3 & 0.38 & 0.19 & 0.0001 & 0.1 & 0.1 & 0.01 & $8,6 \cdot 10^{-6}$ & $\mathrm{Kd}=0.0015$ & \\
\hline & 2 & 1700 & $1.10^{-5}$ & 0.25 & 0.36 & 0.19 & 0.0001 & 0.1 & 0.1 & 0.01 & $8,6 \cdot 10^{-6}$ & $\mathrm{Kd}=0.0015$ & \\
\hline & 3 & 1700 & $1.10^{-7}$ & 0.2 & 0.3 & 0.19 & 0.0001 & 0.05 & 0.01 & 0.01 & $8,6 \cdot 10^{-6}$ & $\mathrm{Kd}=0.0015$ & \\
\hline \multirow{3}{*}{3} & 1 & 1700 & $1,2.10^{4}$ & 0.3 & 0.38 & 0.19 & 0.0001 & 0.1 & 0.1 & 0.01 & $8,6 \cdot 10^{-6}$ & $\alpha=4.02 \quad 10^{-5}$ & $\beta=0.002848$ \\
\hline & 2 & 1700 & $1.10^{-5}$ & 0.25 & 0.36 & 0.19 & 0.0001 & 0.1 & 0.1 & 0.01 & $8,6 \cdot 10^{-6}$ & $\alpha=4.02 .10^{-5}$ & $\beta=0.002848$ \\
\hline & 3 & 1700 & $1.10^{-7}$ & 0.2 & 0.3 & 0.19 & 0.0001 & 0.05 & 0.01 & 0.01 & $8,6 \cdot 10^{-6}$ & $\alpha=4.02 .10^{-5}$ & $\beta=0.002848$ \\
\hline \multirow{3}{*}{4} & 1 & 1700 & $1,2.10-4$ & 0.3 & 0.38 & 0.19 & 0.0001 & 0.1 & 0.1 & 0.01 & $8,6 \cdot 10^{-6}$ & $\alpha=0.7 .10^{-5}$ & $\beta=0.0011111$ \\
\hline & 2 & 1700 & $1.10-5$ & 0.25 & 0.36 & 0.19 & 0.0001 & 0.1 & 0.1 & 0.01 & $8,6 \cdot 10^{-6}$ & $\alpha=0.7 .10^{-5}$ & $\beta=0.0011111$ \\
\hline & 3 & 1700 & $1.10-7$ & 0.2 & 0.3 & 0.19 & 0.0001 & 0.05 & 0.01 & 0.01 & $8,6 \cdot 10^{-6}$ & $\alpha=0.7 .10^{-5}$ & $\beta=0.001111$ \\
\hline \multirow{3}{*}{5} & 1 & 1700 & $1,2.10-4$ & 0.3 & 0.38 & 0.19 & 0.0001 & 0.1 & 0.1 & 0.01 & $8,6 \cdot 10^{-6}$ & $\alpha=5,8,10^{-5}$ & $\beta=0.005 \mathrm{~g}$ \\
\hline & 2 & 1700 & $1.10-5$ & 0.25 & 0.36 & 0.19 & 0.0001 & 0.1 & 0.1 & 0.01 & $8,6 \cdot 10^{-6}$ & $\alpha=5,8 \cdot 10^{-5}$ & $\beta=0.005$ \\
\hline & 3 & 1700 & $1.10-7$ & 0.2 & 0.3 & 0.19 & 0.0001 & 0.05 & 0.01 & 0.01 & $8,6 \cdot 10^{-6}$ & $\alpha=5,8.10^{-5}$ & $\beta=0.005$ \\
\hline
\end{tabular}


a de Langmuir ser a que melhor representa as características de sorção dos materiais geológicos em condições naturais (Verth \& Sposito 1977, Sparks 2001). A isoterma de Freundlich não foi simulada por reefletir, teoricamente, uma condição intermediária entre a Linear e a Langmuir.

Os coeficientes adotados para as isotermas foram baseados em 3 aspectos: (1) gerados a partir de batch tests para diferentes materiais geológicos e íons; (2) os valores para a Isoterma de Langmuir consideraram os dois grupos de poluentes inorgânicos (alcalinos e metálicos), representados por $\mathrm{K}$ e Cd respectivamente; (3) para a isoterma linear adotou-se um valor intermediário entre os extremos do Potássio e do Cádmio.

Cinco cenários foram simulados e que representam diferentes características de sorção, conforme dados da Tabela 2.

As isotermas de sorção são consideradas no modelo por meio do fator de retardamento de acordo com equações apresentadas a seguir. A isoterma de sorção linear é expressa por:

$$
\bar{C}=K d C \quad \text { (2) }
$$

e o fator de retardamento associado por:

$$
R=1+\frac{\rho b}{\theta} K d
$$

A isoterma de sorção de Freundlich é expressa por:

$$
\bar{C}=K f C^{N}
$$

e o fator de retardamento por:

$$
R=1+\frac{\rho b}{\theta} N K f C^{N-1} \text { (5) }
$$

A isoterma de sorção de Langmuir é dada por:

$$
\bar{C}=\frac{K l \bar{S} C}{1+K l C}
$$

Tabela 3 - Características básicas dos minerais encontrados na

\begin{tabular}{|c|c|c|c|c|}
\hline Minerais & $\mathrm{PCZ}^{*}$ & PZNPC & PZSE & $\mathrm{PZNC}$ \\
\hline Hematita & 2.1 & $8.4 \pm 0.1 * *$ & $8.5 * *$ & \\
\hline Caulinita & 4.2 & & & $4.8 * *$ \\
\hline Gibsita & 4.8 & & & \\
\hline Ferro Amorfo & 8.5 & & & \\
\hline Quartzo & $2.0 \pm 0.3 * *$ & & $2.9 \pm 0.9 * *$ & \\
\hline Goetital & $6.1 \pm 0.6 * *$ & $7.7 \pm 0.2 * *$ & $7.3 \pm 0.2 * *$ & \\
\hline
\end{tabular}
área. Sendo: PCZ-Ponto de mudança zero(Point of zero charge); PZNPC - (Point of zero net proton charge); PZSE ou PESZPonto de Efeito salino zero (Point of zero salt effect); e PZNC (Point of zero net charge).

Tabela 5 - Valores do ponto de carga zero $\left(\mathrm{pH}_{0}\right)$ para alguns constituintes do solo (Mitchell, 1993).

\begin{tabular}{lc}
\hline CONSTITUINTE & $\mathrm{pH}_{\mathrm{o}}$ aproximado \\
\hline$\alpha-\mathrm{SiO}_{2}$ (quartzo) & 2,9 \\
$\mathrm{Montmorilonital}$ (Mg-filossilicato) & 2,5 \\
Caulinitit & 4,5 \\
$\alpha-\mathrm{Al}(\mathrm{OH})_{3}$ & 5,0 \\
$\mathrm{TiO}_{2}$ (rutilo) & 5,8 \\
$\alpha-\mathrm{Fe}_{3} \mathrm{O}_{4}$ (magnetita) & 6,6 \\
$\gamma-\mathrm{Fe}_{2} \mathrm{O}_{3}$ & 7,0 \\
$\alpha-\mathrm{FeOOH} \mathrm{O}_{\text {goetita) }}$ & 7,3 \\
$\alpha \mathrm{Al}_{2} \mathrm{O}_{3}$ (coríndom) & 9,0 \\
$\gamma \mathrm{Al}_{2} \mathrm{O}_{3}$ & 8,5 \\
$\alpha-\mathrm{Fe}_{2} \mathrm{O}_{3}$ (hematiti) & 8,5 \\
\hline
\end{tabular}

e fator de retardamento:

$$
R=1+\frac{\rho b}{\theta}\left(\frac{K l \bar{S}}{(1+K l C)^{2}}\right) \text { (7) }
$$

onde $\mathrm{C}=$ concentração de contaminantes dissolvidos na água subsuperficial, $\bar{C}=$ concentração de contaminantes sorbidos, $\rho b$ $=$ massa específica aparente do meio poroso, $\theta=$ porosidade do meio, $S$ = concentração total sorbida, $\mathrm{R}=$ fator de retardamento, $\mathrm{Kd}=$ coeficiente de distribuição, $\mathrm{Kf}=$ isoterma de Freundlich, $\mathrm{N}=$ expoente de Freundlich e $\mathrm{Kl}$ = isoterma de Langmuir.

Quanto às características referentes a dinâmica da concentração de poluentes nas fontes, considerou o Lixão como uma fonte de poluentes continua e com concentração constante, mas que a carga total de poluentes a ser transportada depende da interação da fonte com o meio aquoso. Desta forma a carga total percolada não está definida a priori sendo controlada pelas condições do meio em termos das características hidráulicas e climáticas.

A partir das características hidráulicas dos materiais geológicos e de pontos de calibração simulou-se as condições de fluxo da água na zona saturada. A figura 9 representa as linhas de equipotenciais da cama 1 , em planta. A figura 10 mostra o perfil EW na posição central da área (posição de 325 m norte, Fig. 9), e que contem as linhas equipotenciais e os vetores indicativos da direção e magnitude de fluxo. Nota-se mudanças de magnitude em relação as diferentes camadas de materiais geológicos, de acordo com as características hidráulicas.

RESULTADOSE ENÁLISES Os resultados obtidos a partir das simulações são exxpressos na forma de documentos bidimensionais com isolinhas (mapas) para a profundidade equivalente à metade

Tabela 4 - Distribuição percentual média dos tipos de carga superficial nos principais minerais dos solos.

\begin{tabular}{lcc}
\hline \multicolumn{1}{c}{ MINERAL } & $\begin{array}{r}\text { Tipo e \% } \\
\text { Permanente }\end{array}$ & $\begin{array}{c}\text { de carga } \\
\text { Variável }\end{array}$ \\
\hline Montmorilonita & 95 & 5 \\
Ilita & 52 & 42 \\
Caulinita & 25 & 75 \\
Haloisita & 33 & 67 \\
Gibsita & 0 & 100 \\
Goetita & 0 & 100 \\
Humus & 28 & 72 \\
\hline
\end{tabular}

Tabela 6 - Adsorção seletiva de metais pesados em diferentes solos (Forbes et al 1974, modificado).

\begin{tabular}{ll}
\hline Material & Ordem de Seletividade \\
\hline Caulinita (pH 3,5 - 6) & $\mathrm{Pb}>\mathrm{Ca}>\mathrm{Cu}>\mathrm{Mg}>\mathrm{Zn}>\mathrm{Cd}$ \\
Caulinita (pH 5,5 - 7,5) & $\mathrm{Cd}>\mathrm{Zn}>\mathrm{Ni}$ \\
Ilita (pH 3,5 - 6) & $\mathrm{Pb}>\mathrm{Cu}>\mathrm{Zn}>\mathrm{Ca}>\mathrm{Cd}>\mathrm{Mg}$ \\
Montmorilonita (pH 3,5-6) & $\mathrm{Ca}>\mathrm{Pb}>\mathrm{Cu}>\mathrm{Mg}>\mathrm{Cd}>\mathrm{Zn}$ \\
Montmorilonita (pH 5,5-7,5) & $\mathrm{Cd}=\mathrm{Zn}>\mathrm{Ni}$ \\
Óxidos de Al (amorfos) & $\mathrm{Cu}>\mathrm{Pb}>\mathrm{Zn}>\mathrm{Cd}$ \\
Óxidos de Mn & $\mathrm{Cu}>\mathrm{Zn}$ \\
Óxidos de Fe (amorfos) & $\mathrm{Pb}>\mathrm{Cu}>\mathrm{Zn}>\mathrm{Cd}$ \\
Goetita & $\mathrm{Cu}>\mathrm{Pb}>\mathrm{Zn}>\mathrm{Cd}$ \\
Ácido Fúlvico (pH 5,0) & $\mathrm{Cu}>\mathrm{Pb}>\mathrm{Zn}$ \\
Ácido Húmico (pH 4-6) & $\mathrm{Cu}>\mathrm{Pb}>\mathrm{Cd}>\mathrm{Zn}$ \\
Material de origem vulcânica & $\mathrm{Pb}>\mathrm{Cu}>\mathrm{Zn}>\mathrm{Cd}>\mathrm{Ni}$ \\
Solos minerais (pH 5,0) - (sem matéria orgânica) & $\mathrm{Pb}>\mathrm{Cu}>\mathrm{Zn}>\mathrm{Cd}$ \\
Solos minerais (com 20 a 40 g/kg de matéria orgânica) & $\mathrm{Pb}>\mathrm{Cu}>\mathrm{Cd}>\mathrm{Zn}$ \\
\hline
\end{tabular}


da espessura da camada, e seções ortogonais, em $90^{\circ}$, com a disposição dos materiais geológicos, isolinhas e vetores em profundidade. Os resultados são apresentados de maneira a permitir a avaliação do comportamento espacial e/ou temporal dos poluentes frente às diferentes características simuladas.

Os comprimentos e as larguras máximas atingidas pela frente de contaminação estão representados na Tabela 7, e foram obtidas para as isolinhas mínimas de 20,5 e $0.2 \mathrm{mg} / \mathrm{l}$, para as camadas $1,2 \mathrm{e}$ 3 , respectivamente. As isolinhas foram consideradas a partir dos mapas de isovalores das frentes obtidos para a posição correspondente à metade da espessura de cada camada em cada cela.

A análise dos resultados e as condições de simulação foram desenvolvidas sob os aspectos geral e específico. No geral, os pontos considerados referenciais foram a distribuição espacial das isolinhas obtidas a partir da eletroresistividade, a distribuição na porção interior ao limites externos da fonte de poluição (lixão) e a relação entre a geometria das camadas e da frente de poluição. No aspecto específico, as análises consideraram as dimensões das isolinhas mínimas, as concentrações máximas no topo de cada camada e geometria das isolinhas de máxima concentração, e comparação entre cenários.

Os valores do primeiro cenário foram: 3650 dias com comprimento de 116,173 e largura de $35,99 \mathrm{~m} ; 4380$ dias com comprimento de 336,092 e largura de $180,23 \mathrm{~m}$; e 7300 dias com comprimento de 615,385 e largura de $213,52 \mathrm{~m}$. Para o segundo, tempo de 7300 dias, com comprimento de 370,492 e largura de $177,049 \mathrm{~m}$. Os demais tempos não foram atingidos com concentrações significativas.

Em termos gerais, observou-se que (1) nas condições simula- das, as concentrações na $3^{\circ}$ camada foram significativas a partir do tempo 4380 dias; (2) a geometria das camadas utilizadas na simulação influiu na distribuição espacial da frente de contaminação para todas as condições simuladas; (3) a partir dos resultados apresentados na Tabela 7, verifica-se que as dimensões (comprimento e largura) das frentes de contaminação, considerando as isolinhas mínimas, são bastante variáveis, com desvio padrão significativos em relação as médias.

Baseando-se nas formas de distribuição espacial e temporal de concentração/resistividade aparente obtidas por eletroresistividade, as simulações 3,4 e 5 são as que apresentam resultados mais compatíveis com oś obtidos por eletroresistividade, ou seja quando aspectos de sorção são considerados.

A Tabela 8 contem os valores de concentrações máximas para cada camada, nas diferentes condições de simulação. Verifica-se uma diminuição do desvio padrão em relação à média com o tempo nas simulações com o mesmo tipo de fonte. Porém, a diminuição é mais sensível na camada 1 , e menor na camada 3 .

Observou-se que a contaminação em área a partir do topo da segunda camada é irregular, com ilhas de concentração com valores diferentes, fato este também verificado na geofísica (Fig. 7).

Cenário 1 - Como este cenário representa uma condição na qual não se considera o efeito da sorção, o transporte é predominantemente por advecção e os níveis de contaminação são elevados. Observa-se que para o tempo de 7300 dias a $3^{\circ}$ camada é atingida pelos poluentes em concentração superiores a 120ppm, como mostra a seção longitudinal ao lixão (Fig. 11).

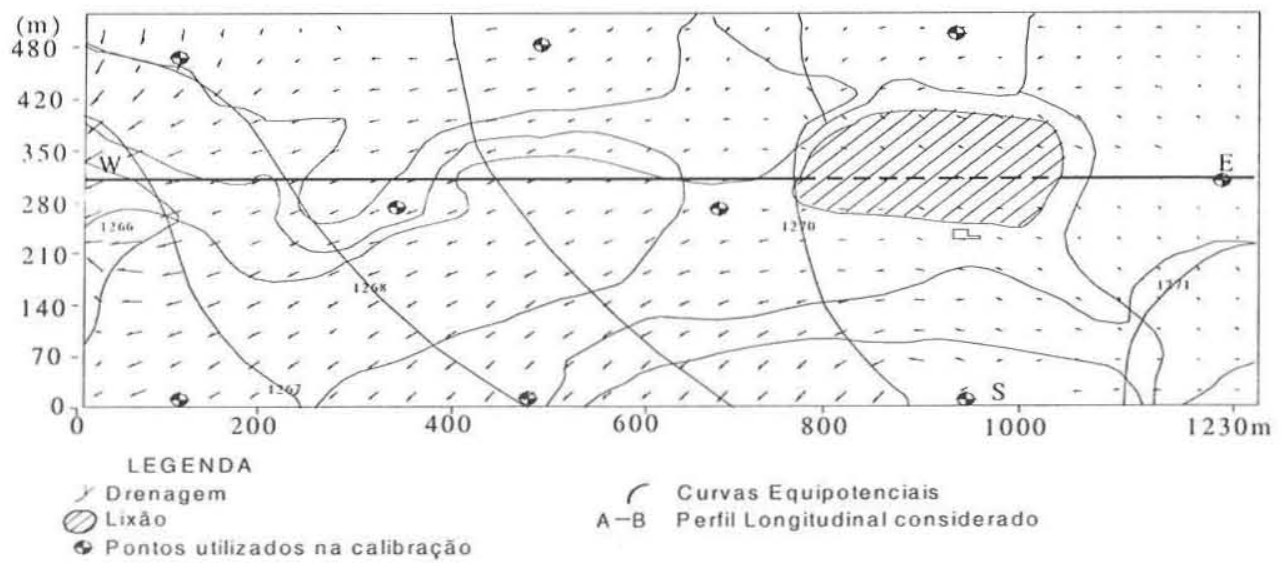

Figura 9-Linhas equipotenciais, direções de fluxo e posições da linha base (NS) e (EW) (linhas retas indicam o posicionamento dos caminhamentos de geofísica).

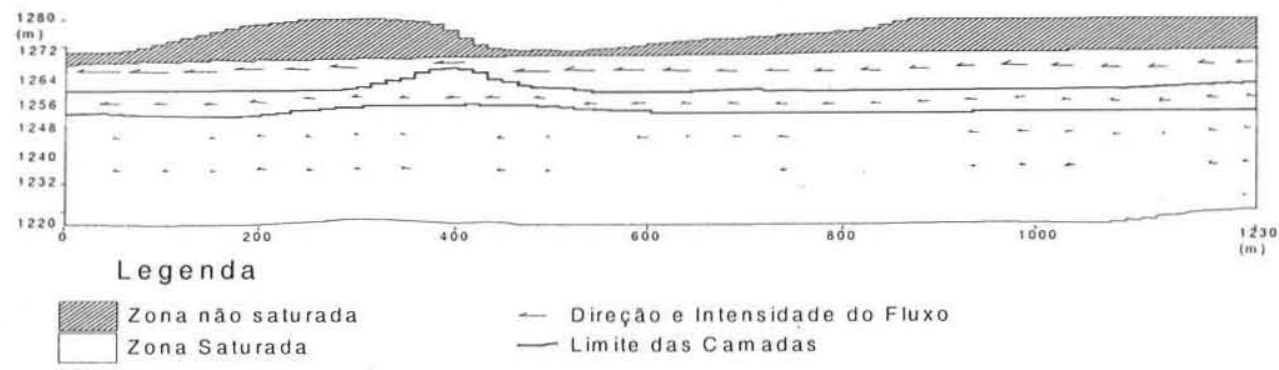

Figura 10-Seção longitudinal E-W subparalela ao fluxo nas camadas 1, 2 e 3. 
O topo da camada 3 pode ser atingido por concentrações acima de 70 ppm desde o tempo de 1825 dias e atinge 170 ppm em 7300 dias. A figura 12 mostra o mapa da frente de contaminação para os tempos de 4380 e 7300 dias.

Cenário 2 - Neste cenário considerou a Isoterma de Sorção Linear e os resultados refletem o quanto irreal é a consideração desta isoterma neste caso, visto que a frente de contaminação, com base nas isolinhas mínimas não atinge valores significativos nem para o tempo de 7300 dias, para as três camadas (Fig. 13). A figura 14 mostra a distribuição da frente em perfil longitudinal (relação concentração e profundidade) nos vários tempos simulados.

Cenário 3 - Os resultados obtidos por este modelo apresentam uma boa correlação com os dados obtidos em campo (Fig. 5) tanto entre relação aos níveis de contaminação quanto à distribuição espacial e a forma de distribuição dos contaminantes no tempo (Figs. 15 e 16).

Cenário 4 - As concentrações para a camada 2 são menores neste caso até o tempo de 4380 dias, porém para 7300 dias a concentração é maior que no cenário 3 (145ppm). Ressalta-se que a partir de 3650 dias não ocorreu avanço da frente para a camada 3 , mantendo até 7300 dias a concentração de 50 ppm (Fig. 17). A figura 18 mostra a distribuição da frente de contaminação em relação à profundidade para os vários tempos simulados em seção longitudinal ao lixão.

Cenário 5 - Em relação ao cenário 4, as maiores variações ocorrem para a camada 2 em termos de concentração máxima até 4380 dias, assim como no comprimento da isolinha mínima para período de 7300 dias Na Fig. 19 observa-se a distribuição da frente de contaminação em relação à profundidade nos vários tempos simulados representando a seção longitudinal ao lixão. A figura 20 mostra a distribuição das frentes nas duas camadas superiores para os tempos de 4380 e 7300 dias. De maneira geral, apesar das diferenças nos valores de sorção, as frentes de contaminação apresentam-se com muitas semelhanças.

Os resultados em termos de dimensões e intensidades para os cenários 3, 4 e 5 são muito semelhantes com diferenças inferiores a 10\% entre si. Tais grandezas estão compatíveis com os valores dos parâmetros das isotermas de sorção de Langmuir. As dimensões constantes da Tabela 8 indicam valores maiores de comprimento e largura para as frentes de contaminantes resultantes do cenário 4, que utiliza os menores valores para sorção, enquanto, os valores referentes aos cenários 3 e 5 são próximos, também refletindo os diferentes valores de sorção adotados.

Quando às intensidades observadas nos resultantes das simulações dos cenários 3, 4 e 5 (topos das 3 camadas), as diferenças são menores em porcentagens do que para as dimensões, refletindo a combinação dos valores de sorção com os valores das razões de dispersividade.

As dimensões e as intensidades das frentes resultantes da simulação do cenário 2 são muito diferentes das obtidas para os cenários 3,4 e 5 e dos resultados obtidos pela eletroresistividade / calibração. Tais resultados demonstraram que, mesmo para baixas concentrações de contaminantes, a isoterma Linear deve ser utilizada com cuidado.

Analisando os valores de intensidade máximos e dimensões da frente para a camada 1, observa-se uma semelhança significativa, resultante da elevada condutividade hidráulica que potencializa o transporte de contaminantes por advecção, e portanto minimiza os efeitos da dispersividade e sorção.

Ao analisar o comportamento da intensidade para a camada 3 em todas as simulações observa-se a tendência dos valores serem semelhantes para os tempos maiores que 7300 dias, com exceção do cenário 2. Condição prevista, visto que o efeito da sorção considerando a isoterma de Langmuir é ser nula para grandes

Tabela 8 - Concentrações máximas, para o topo de cada camada, nas diferentes condições e tempo simulados.

\begin{tabular}{cccccc}
\hline Cenários & Camada & 1825 dias & 3650 dias & 4380 dias & 7300 dias \\
\hline \multirow{3}{*}{1} & 1 & 560 & 560 & 560 & 570 \\
& 2 & 260 & 220 & 220 & 270 \\
& 3 & 80 & 90 & 120 & 170 \\
\hline \multirow{2}{*}{2} & 1 & 520 & 520 & 520 & 550 \\
& 2 & 120 & 120 & 120 & 120 \\
& 3 & 0 & 0 & 0 & 20 \\
\hline \multirow{3}{*}{3} & 1 & 520 & 540 & 600 & 600 \\
& 2 & 150 & 190 & 190 & 200 \\
& 3 & 20 & 40 & 50 & 80 \\
\hline \multirow{3}{*}{4} & 1 & 560 & 570 & 570 & 600 \\
& 2 & 140 & 170 & 170 & 170 \\
& 3 & 20 & 50 & 50 & 50 \\
\hline \multirow{2}{*}{5} & 1 & 550 & 570 & 600 & 600 \\
& 2 & 150 & 170 & 170 & 170 \\
& 3 & 20 & 40 & 50 & 70 \\
\hline
\end{tabular}

Tabela 7 - Comprimentos e larguras máximas das frentes para a isolinha mínima de 20 e 5.0mg/l

\begin{tabular}{|c|c|c|c|c|c|c|c|c|c|}
\hline Camada ** & \multirow[b]{2}{*}{ Mínima } & \multicolumn{3}{|c|}{1} & & \multicolumn{4}{|c|}{2} \\
\hline Isolinha & & & $20 \mathrm{mg} / \mathrm{l}$ & & & & $5 \mathrm{mg} / \mathrm{l}$ & & \\
\hline Tempo & (dias) & 1825 & 4380 & 3650 & 7300 & 1825 & 3650 & 4380 & 7300 \\
\hline \multirow[t]{2}{*}{ Cenário 1} & Compr.* & 383,220 & 600 & 692,74 & 958.998 & 327,146 & 543,333 & 621,81 & 892,414 \\
\hline & Largura & 200,000 & 262,529 & 290,398 & 355,353 & 217,633 & 240,952 & 291,879 & 354,023 \\
\hline \multirow[t]{2}{*}{ Cenário 4} & Compr.* & 209,302 & 226,681 & 247,059 & 277,449 & 164,045 & 191,142 & 195,402 & 225,287 \\
\hline & Largura & 181,395 & 194,794 & 216,941 & 218,679 & 76,854 & 162,704 & 166,437 & 177,012 \\
\hline \multirow[t]{2}{*}{ Cenário 5} & Compr.* & 377,130 & 591,011 & 669,090 & 949,425 & 275,462 & 367,889 & 515,862 & 758,796 \\
\hline & Largura & 201,345 & 267,415 & 289,636 & 326,896 & 103,529 & 172,018 & 163,218 & 280,092 \\
\hline \multirow[t]{2}{*}{ Cenário 6} & Compr.* & 376,871 & 646,154 & 672,811 & 952,184 & 278,360 & 422,738 & 539,07 & 784,722 \\
\hline & Largura & 217,234 & 249,417 & 317,972 & 331,494 & 99,537 & 201,856 & 208,372 & 321,759 \\
\hline \multirow[t]{2}{*}{ Cenário 7} & Compr.* & 378,190 & 593,135 & 672,558 & 951,855 & 265,412 & 437,138 & 529,004 & 781,215 \\
\hline & Largura & 192,575 & 259,038 & 293,023 & 328,613 & 99,546 & 212,811 & 213,324 & 321,621 \\
\hline \multirow[t]{2}{*}{ Média } & Compr.* & 344,943 & 411,516 & 565,380 & 817,982 & 262,085 & 392,448 & 413,423 & 688,487 \\
\hline & Largura & 198,510 & 246,639 & 281,594 & 312,207 & 119,420 & 198,068 & 208,646 & 290,901 \\
\hline Desvio & Compr.* & 75868.92113 & 284286.32 & 212220.46 & 302188.21 & 59790.601 & 129236.42 & 188925.74 & 264075.5 \\
\hline Padrĩo & Largura & 13124.33761 & 29721.586 & 38000.577 & 53539.649 & 55902.798 & 31622.608 & 51949.48 & 68861.928 \\
\hline
\end{tabular}

(* Comprimento; ** - A terceira camada foi atingida com valores superiores a $0.2 \mathrm{mg} / \mathrm{l}$ apenas no primeiro cenário). 

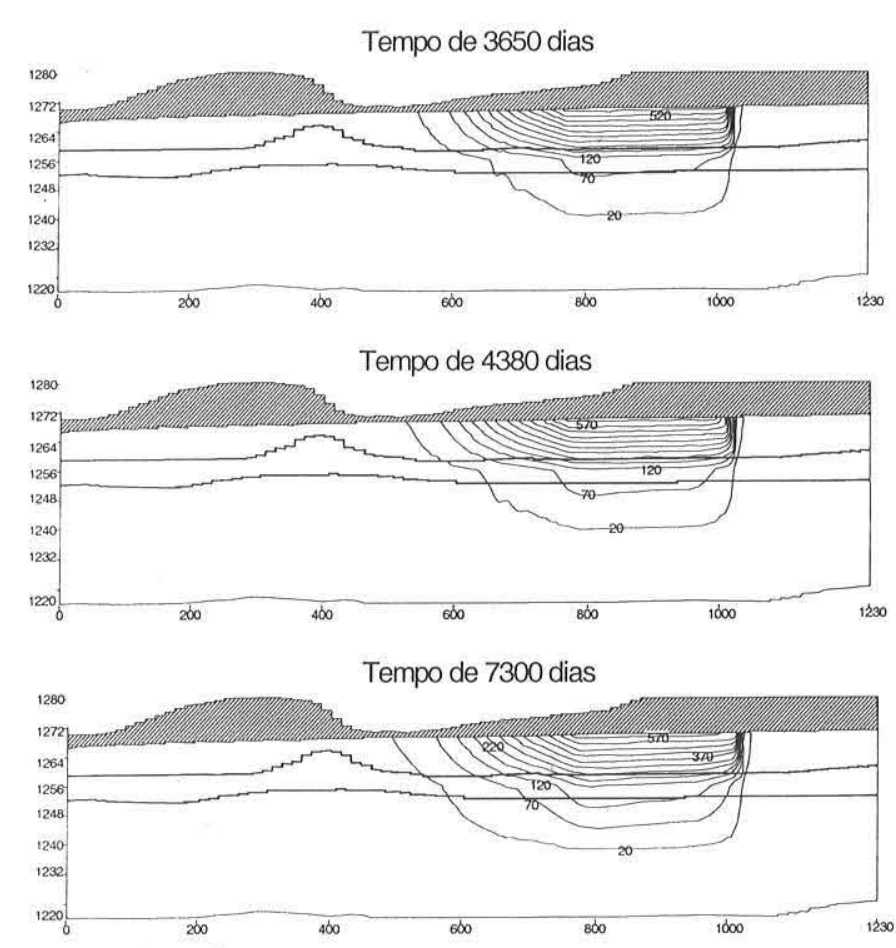

Legenda

Zona Năo Saturada $\cup$ Linhas de Isovalores

Zona Saturada - Limites das camadas

Figura II - Seção longitudinal ao comprimento do lixão mostrando a distribuição da frente de contaminação nos diversos tempos simulados para o cenário I (Posição do perfil na Fig. 9). espaços temporais, enquanto para a isoterma linear (cenário 2) isto não ocorre.

Ao comparar os resultados das simulações 1, 2, 3, 4 e 5 verificase que os cenários 3 e 5 apresentam boa compatibilidade com os dados obtidos por geofísica constantes das figs. 6 e 7 tanto na geometria da frente quanto nos valores de concentração.

Nos resultados dos cenários 3 e 5 observa-se a influência das características de sorção, mais acentuada para os tempos menores (até 4380 dias), mas que tende a se igualar para os tempos maiores (7300 dias), como esperado em termos teóricos.

CONCLUSÕES Os resultados das simulações reforçam a importância de uma investigação geológica- geotécnica adequada para a caracterização dos materiais geológicos, em termos de mineralogia, $\mathrm{pH}, \mathrm{CTC}$, porosidade e relações espaciais, e do uso de técnicas combinadas para avaliação da frente de contaminação.

Ressalta-se que o programa apresenta limitações para simulações com a isoterma de Freundlich, principalmente quando considera materiais geológicos com parâmetros específicos para a equação, porém obtidos em laboratório e, portanto reais. As simulações com a isoterma de Langmuir apresentaram boa correlação com os resultados da eletroresistividade, com destaque para o cenário 3 , conforme destacado por extenso número de estudos.

A obtenção de parâmetros de sorção dos diferentes materiais geológicos é fundamental nos estudos de transporte de poluentes, porém os métodos de obtenção devem ser aprimorados, principalmente com controle das variáveis que os influenciam.

Os ensaios de eletroresistividade de caminhamento elétrico utilizando pequenos espaçamentos permitem a interpretação e elaboração de mapas e seções verticais das plumas de contaminação com boa precisão, e permitem a calibração de modelos e o monitoramento continuo.

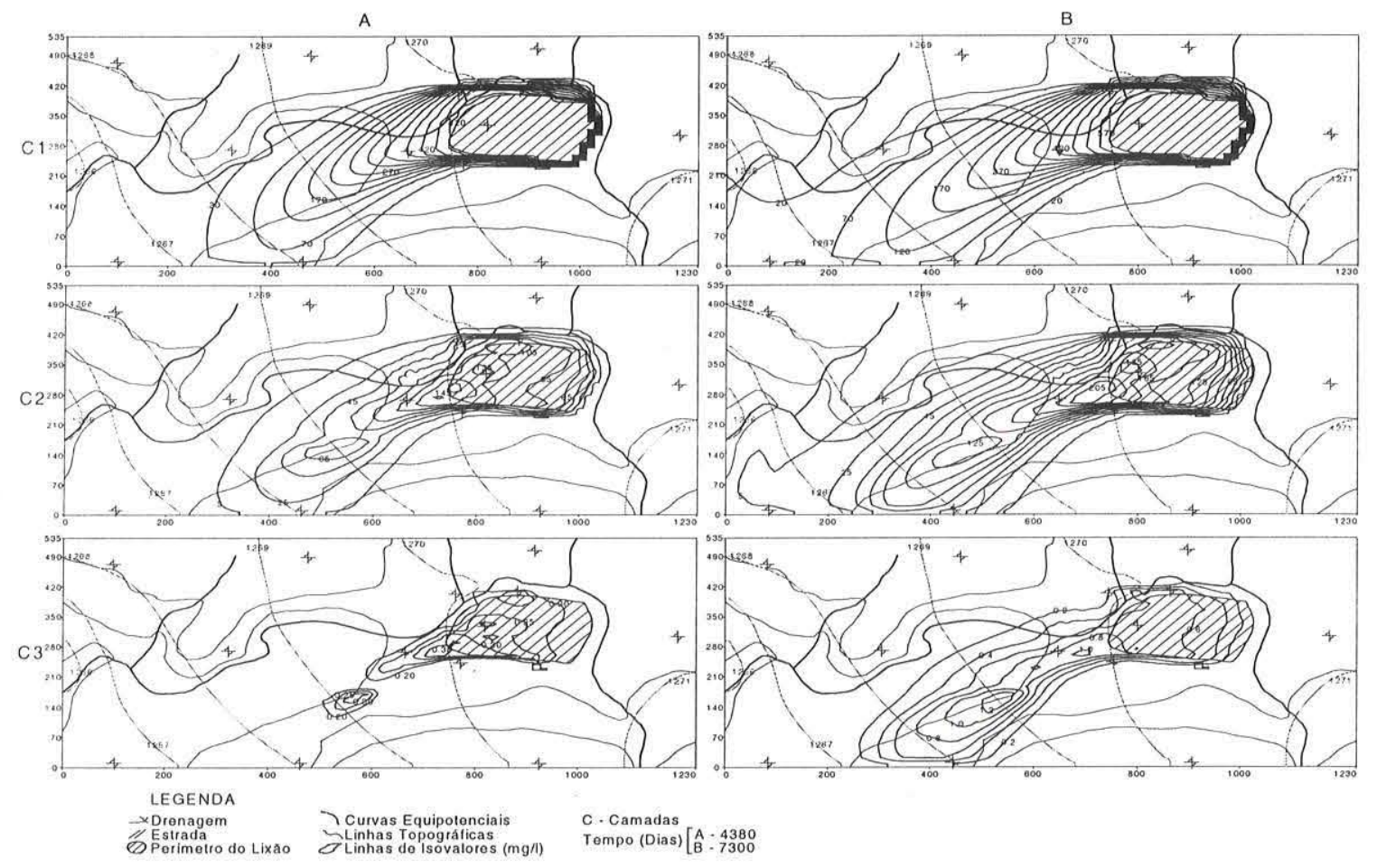

Figura 12 - Mapas da frente de contaminação para os tempos de 4380 e 7300 dias (Cenário 1). 


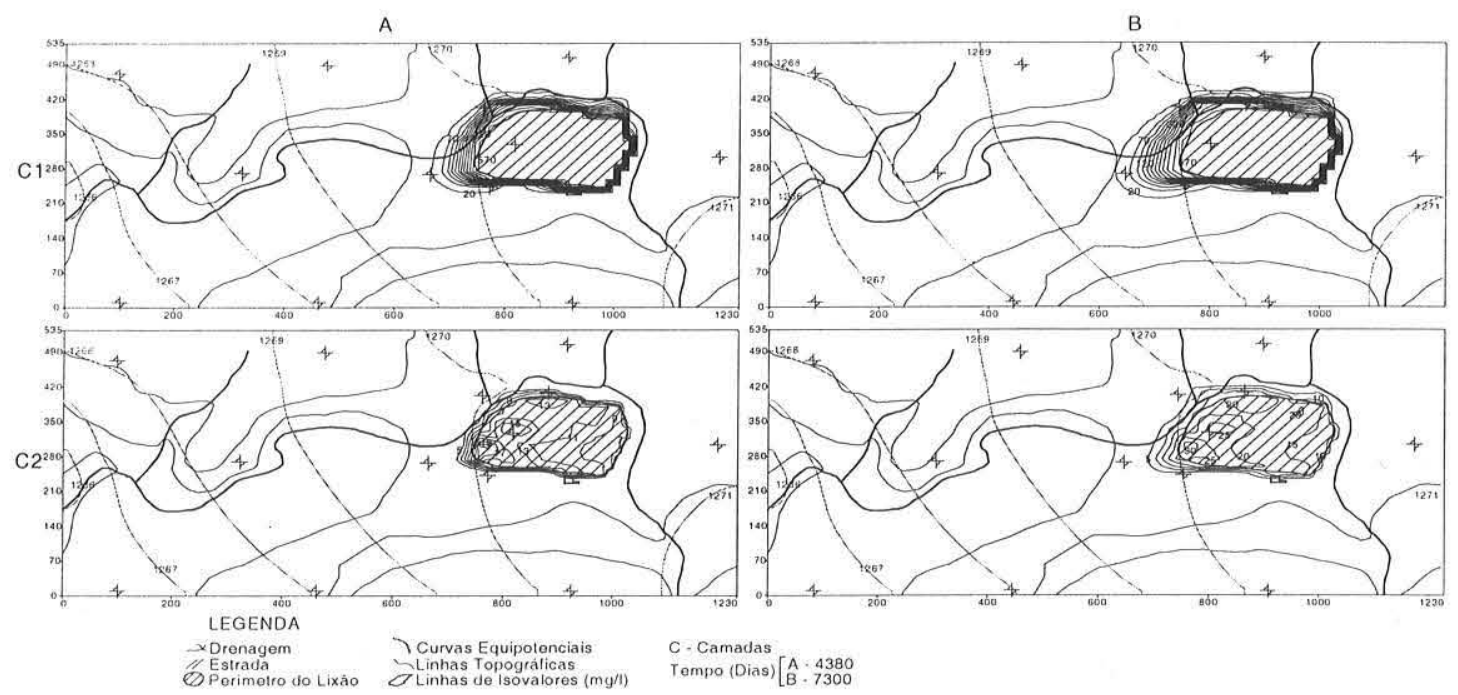

Figura 13 - Frente de contaminação representando as isolinhas mínimas para o Cenário 2.

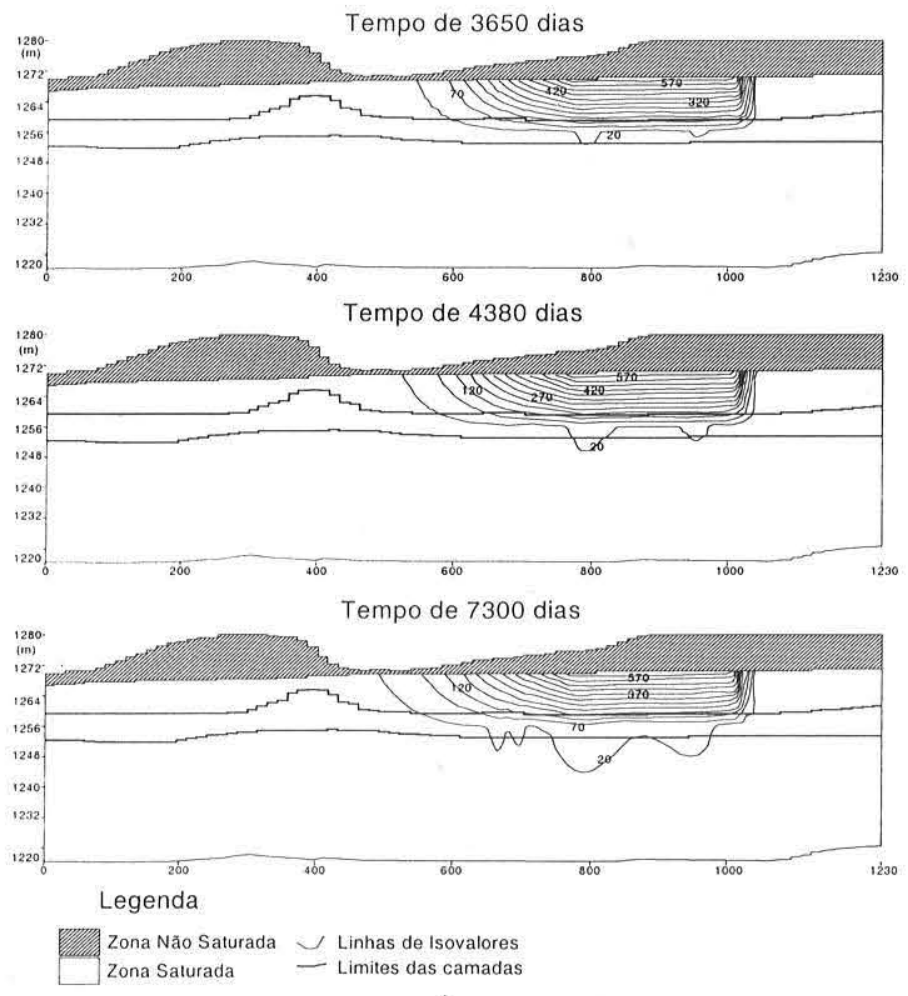

Figura 14 - Perfis longitudinais resultantes da simulação 2 para os vários tempos.

Agradecimentos À Coordenação de Aperfeiçoamento do Pessoal de Nível Superior (CAPES) e à Fundação de Amparo a Pesquisa
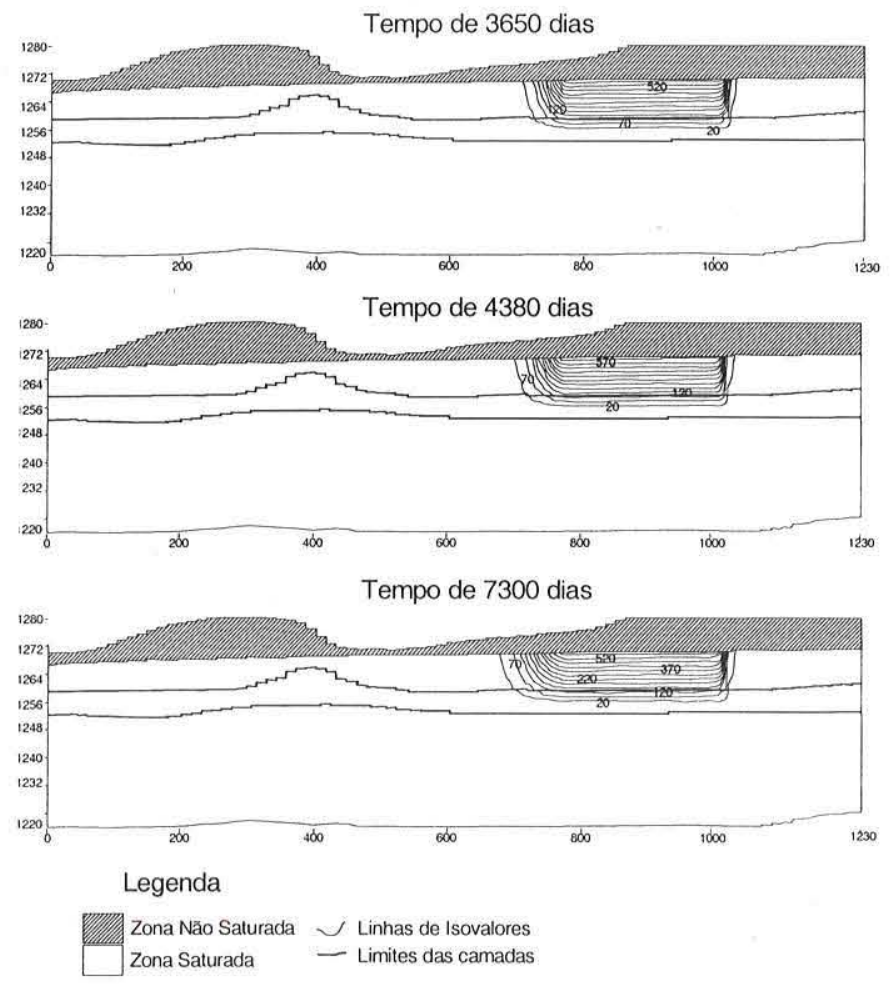

Figura 16 - Perfis longitudinais resultantes da simulação 3 para os vários tempos.

do Estado de São Paulo (Processo 00/03027-7) pelo apoio financeiro. Aos revisores da RBG pelas sugestões ao manuscrito.

\section{Referências}

Burnett R.D. \& Frind E.O. 1987. An alternating direction galerkin techniques for simulation of groundwater contaminant transport en three dimensions, 2. Dimensionality effects. Water Resour: Res. 23:695705.
Carlstron Filho C.,Corrêa Filho D., Bottura J.A. 1978. Caracterização hidrogeotécnica baseada em dados piezométricos e características hidrodinâmicas do maciço da mina de Urânio Osamu Utsumi, Poços de Caldas, MG. In: A BGE, Congr. Geol. de Eng., 10, Anais, 2: 297 - 


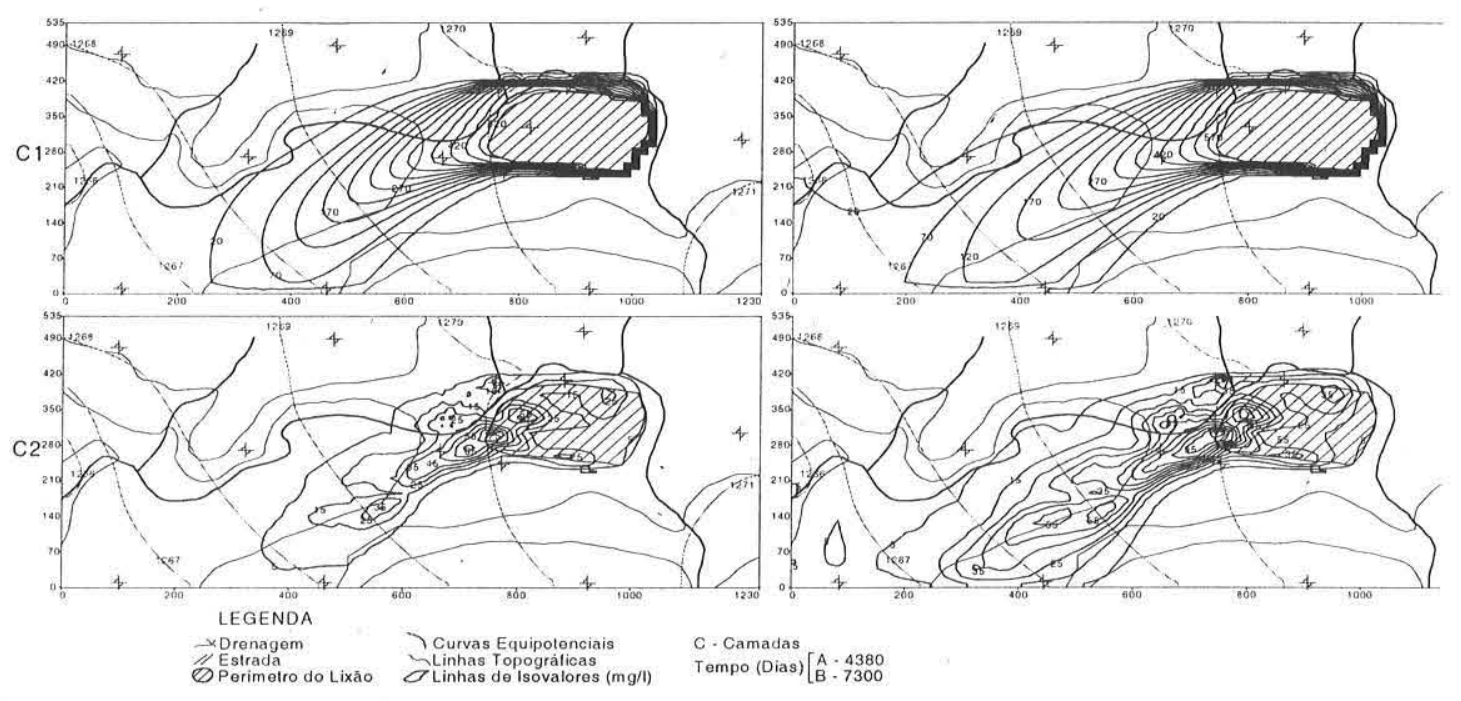

Figura 15 - Frente de contaminação representando as isolinhas mínimas para o Cenário 3.

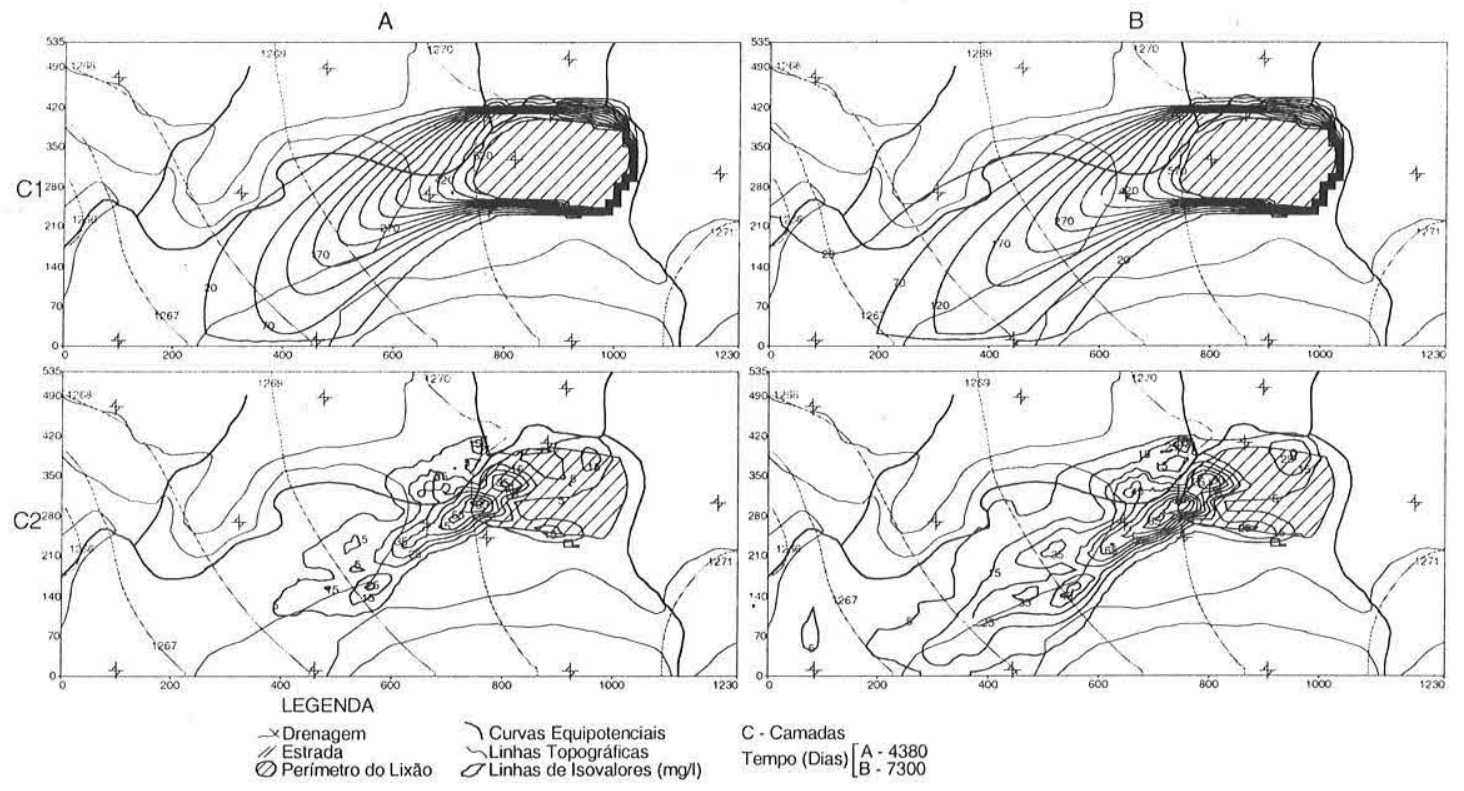

Figura 17 - Frente de contaminação representando as isolinhas mínimas para o Cenário 4.

de Caldas, MG. In: ABGE, Congr: Geol. de Eng., 10, Anais, 2: 297309.

Dey A. \& Morison H.F. 1979. Receptivity modeling for arbitraries shaped three-dimensional structures. Geophysics, 44:753-780.

Elis V.R. 1998. Avaliação da Aplicação de métodos elétricos de prospecção geofísica no estudo de áreas utilizadas para disposição de resíduos. Tese de Doutorado, IGCE/UNESP, 264p.

Forbes E.A., Posner A.M., Quirk J.P. 1974. The specific adsorption of inorganic $\mathrm{Hg}$ (II) species and $\mathrm{Co}$ (II) complex ions on geothite. J. Colloid Interface Sci., 49:403-409.

Geological Society. 1990. Tropical residual soil. The Quartely Journal of Engineering Geology, 23(1).

Mahamed A.M.O. \& Antia H.E. 1998. Geoenvironmental Engineering. Developments in Geotechnical Engineering, 82. Elservier. 707p.
Mcdonald M.G. \& Harbaugh A.W. 1988. A modular three-dimensional finite-difference groundwater flow model. US. Geological Survey Techniques of water-resources investigations, Book 6. Chap. Ai, $586 \mathrm{p}$.

Meju, M.A. 2000. Geoeletrical investigation of old/abandoned, covered landfill sites in urban areas: model development with a genetic diagnosis approach. J. Appl. Geoph., 44:115-150.

Mitchell J.K. 1993. Fundamentals of Soil Behaviour. John Wiley and Sons, New York, 422p.

Olsthoorn T.N. 1999. A comparative review of analytic and finite models used at the Amsterdam Water Supply. J. Hydrol., 226:139143.

Polemio M. \& Romanazzi L. 1999. Numerical simulation of ground water protection works for an industrial waste dump. Bull. Eng. 

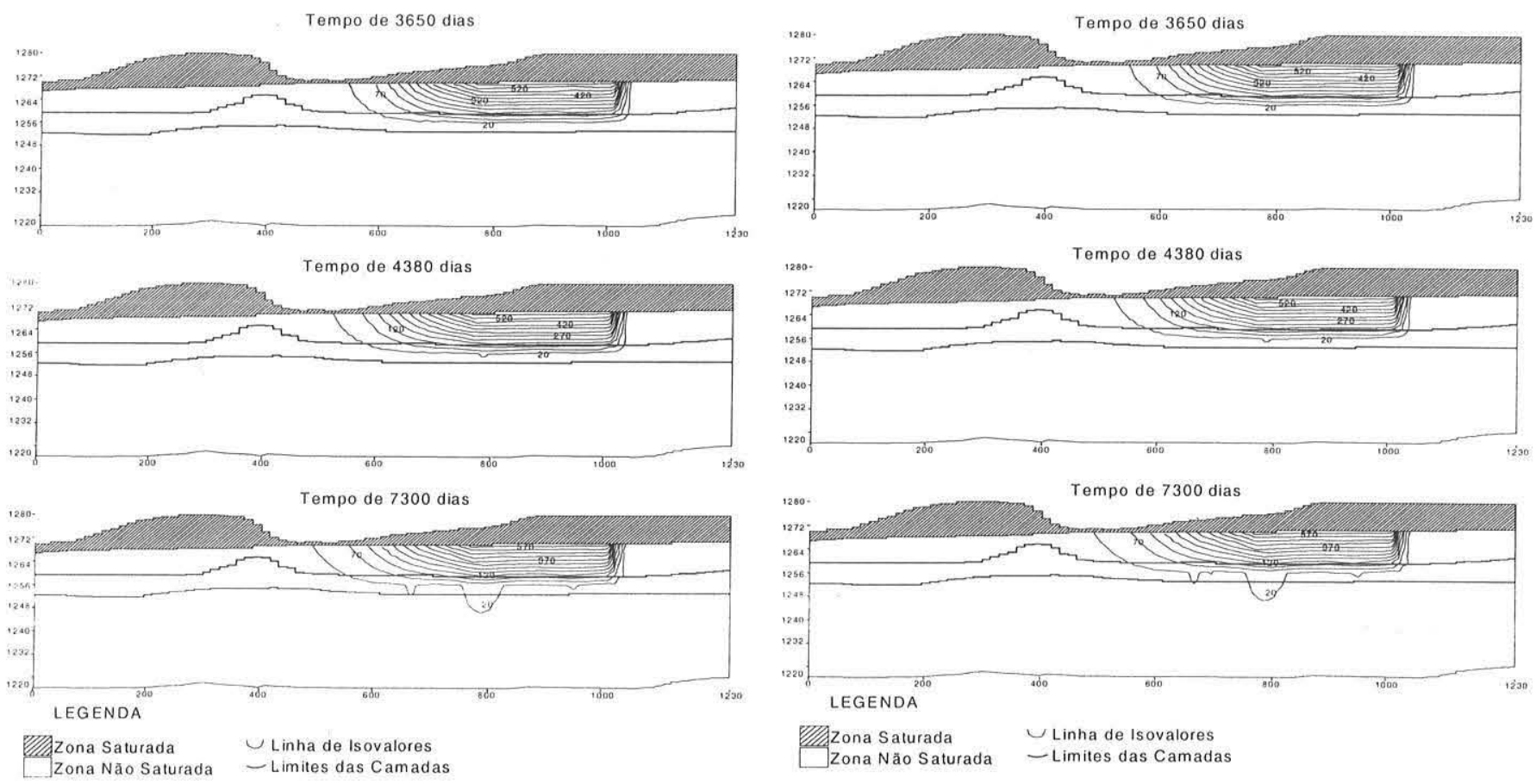

Figura 18 - Perfis longitudinais resultantes da simulação 4 para os vários tempos.

Figura 19 - Perfis longitudinais resultantes da simulação 5 para os vários tempos.

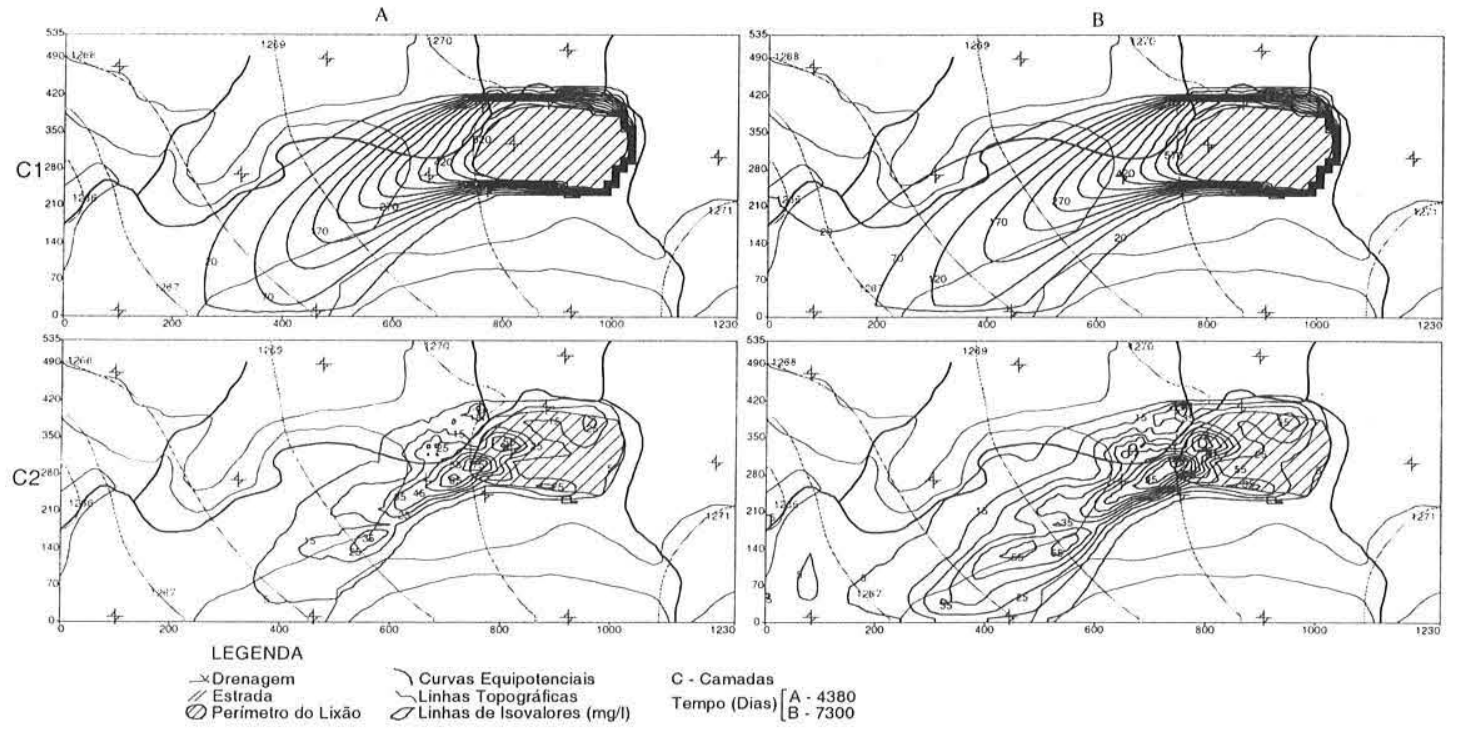

Figura 20 - Frente de contaminação representando as isolinhas mínimas para o Cenário 5.

Geol. Environment., 57:253-261.

Pollock D.W. 1988. Semi analytical computation of path lines for finite-difference models. Groundwater, 26:743 - 750.

Sparks D. L. 2001. Elucidating the fundamental chemistry of soils: past and recent achievements and future frontiers. Geoderma, 100:303-319

Verth I.A. \& Sposito G. 1977. On the use of the Langmuir equation in the interpretation of adsorption phenomena. Soil Sci., 33:95-113

Winston R.B. 1999. MODFLOW - related freeware and shareware resources on the internet. Computer \& Geosciences, 25:377-382.

Zheng C. 1992. A modular Three-dimensional transport model. Golden. CO: International Groundwater Modelling Center. IGWMC - TPS, 7:6-32.

Manuscrito A-1371

Recebido em 29 de setembro de 2002 Revisão dos autores em 25 de fevereiro de 2004 Revisão aceita em 25 de março de 2004 